\title{
Regional differences in the impact of the COVID-19 pandemic on food sufficiency in California, April-July 2020: implications for food programmes and policies
}

\author{
Evelyn Blumenberg ${ }^{1, *}$, Miriam Pinski ${ }^{1}$, Lilly A Nhan ${ }^{2} \odot$ and May C Wang ${ }^{2}$ \\ 'Department of Urban Planning, Luskin School of Public Affairs, University of California, Los Angeles, 3250 Public \\ Affairs Building, Los Angeles, CA 90095, USA: '2Department of Community Health Sciences, Fielding School of Public \\ Health, University of California, Los Angeles, 650 Charles E Young Dr S, Los Angeles, CA 90095, USA
}

Submitted 4 January 2021: Final revision received 21 April 2021: Accepted 26 April 2021: First published online 30 April 2021

\begin{abstract}
Objective: To evaluate regional differences in factors associated with food insufficiency during the initial months of the COVID-19 pandemic among three major metropolitan regions in California, a state with historically low participation rates in the Supplementation Nutrition Assistance Program, the nation's largest food assistance programme.

Design: Analysis of cross-sectional data from phase 1 (23 April-21 July 2020) of the US Census Household Pulse Survey, a weekly national online survey.

Setting: California, and three Californian metropolitan statistical areas (MSA), including San Francisco-Oakland-Berkeley, Los Angeles-Long Beach-Anaheim and Riverside-San Bernardino-Ontario MSA.

Participants: Adults aged 18 years and older living in households.

Results: Among the three metropolitan areas, food insufficiency rates were lowest in the San Francisco-Oakland-Berkeley MSA. Measures of disadvantage (e.g., having low-income, being unemployed, recent loss of employment income and pre-pandemic food insufficiency) were widely associated with household food insufficiency. However, disadvantaged households in the San Francisco Bay Area, the area with the lowest poverty and unemployment rates, were more likely to be food insufficient compared with those in the Los Angeles-Long BeachAnaheim and Riverside-San Bernardino-Ontario MSA.

Conclusions: Food insufficiency risk among disadvantaged households differed by region. To be effective, governmental response to food insufficiency must address the varied local circumstances that contribute to these disparities.
\end{abstract}

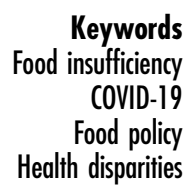

The COVID-19 pandemic has caused unprecedented disruptions to the social and economic livelihoods of Americans. While 'safer-at-home' (also known as 'shelterin-place') and social distancing orders across the USA were important for mitigating the spread of COVID-19, these orders affected people's ability to work and, consequently their financial resources for purchasing food. With the closure of non-essential businesses, millions of Americans experienced job and income losses during the pandemic. For families with children, the physical closure of schools and child care facilities limited their ability to receive food for their children through critical federal food assistance programmes such as school meals ${ }^{(1)}$. At the same time, the economic disruptions from COVID-19 coupled with shifts away from institutional and restaurant food consumption and towards consuming food at home caused shocks to the food system and resulted in increased food prices early during the pandemic ${ }^{(2)}$.

These rapid changes in employment and food access led to a rise in food insecurity, defined as the limited or uncertain availability of nutritionally adequate and safe foods or limited or uncertain ability to acquire acceptable foods in socially acceptable ways' ${ }^{\text {(3) }}$. In high-income countries, such as the USA, food insecurity is associated with increased risk of diet-related chronic health conditions, such as obesity, diabetes and hypertension, and also with 
poor sleep and depression ${ }^{(4)}$. Hence, food insecurity, if not addressed promptly, can be expected to widen existing health disparities during the pandemic.

Early estimates suggest that nearly $40 \%$ of US adults experienced food insecurity in the last week of March $2020^{(5)}$; another report estimated that $25 \%$ of US adults experienced food insecurity from April to June $2020^{(6)}$. In comparison, the food insecurity rate for the nation was $10 \%$ in $2019^{(7)}$. Patterns of food insecurity vary across population groups. Prior to the COVID-19 pandemic, food insecurity rates were highest among low-income, Black and Latinx households, and adults with children ${ }^{(7)}$, and these disparities have continued during the pandemic ${ }^{(8)}$.

In March 2020, Congress passed the Coronavirus Aid, Relief, and Economic Security (CARES) Act, which provided direct economic assistance to Americans, including stimulus payments of up to $\$ 1200$ for eligible adults and $\$ 500$ per qualifying child under age 17 years and expansion of unemployment benefits. Distribution of the first round of stimulus payments from the CARES Act started in April 2020. Early evidence suggests that stimulus payments and expansion of unemployment benefits through the CARES Act may have mitigated - but did not put an end to - food insecurity. For example, the Understanding the Coronavirus in America tracking survey reported that food insecurity in Los Angeles county, the most populous county in the USA, decreased from $26 \%$ in April-May 2020 to $10 \%$ in June-July $2020^{(9)}$. Among those who were food insecure in April-May 2020 but food secure in June-July 2020, $24.6 \%$ received unemployment insurance and $17.2 \%$ received economic stimulus funds. In comparison, among those who remained food insecure throughout April-July 2020 , only $11.1 \%$ received unemployment insurance and $11.6 \%$ received economic stimulus funds. These findings suggest that financial assistance programmes may have assisted some families, but did not reach all families and did not provide sufficient relief.

Through the Census Household Pulse Survey (CHHPS), the Census Bureau has been measuring changes in food insufficiency during this pandemic, beginning data collection via the internet on 23 April $2020^{(10)}$. Food insufficiency - defined simply as having not enough food to eat - is considered a component of the broader concept of food insecurity $^{(3)}$. Monitoring food insufficiency is important as it informs the implementation of programmes and policies designed to ensure that every household has access to enough food.

We used data from the CHHPS to examine regional differences in the determinants of food insufficiency in three diverse California metropolitan statistical areas (MSA): San Francisco-Oakland-Berkeley (SF-Bay Area), Los Angeles-Long Beach-Anaheim (LA-Anaheim) and Riverside-San Bernardino-Ontario (Riverside-San Bernardino). California was the first state to implement a statewide stay-at-home order (on 20 March 2020) and in the week of 12 September 2020, over $2 \cdot 8$ million people had claimed unemployment insurance in California, more than any other state ${ }^{(11)}$.

The effects of the COVID-19 pandemic on food insufficiency can be expected to vary across regions of the state, as the regions differ across many dimensions. For example, among the three MSA, LA-Anaheim and Riverside-San Bernardino had the highest unemployment rates (5.7 and $5.1 \%$, respectively), and the SF-Bay Area the lowest (3.5\%) in March $2020^{(12)}$. From March to May, unemployment rates increased substantially across the state. However, while May unemployment rates continued to remained higher in LA-Anaheim and Riverside-San Bernardino (19.1 and $14.9 \%$, respectively) than the SFBay Area (12.7\%), the percentage increase was largest in the SF-Bay Area ${ }^{(13)}$. There also are differences in inequality and the cost of living across the three MSA. Income inequality - measured as the ratio between the household income of those in the 95th percentile relative to those in the 20th percentile - is substantially higher in the SF-Bay Area than the other two metropolitan areas ${ }^{(14)}$. The cost of living in the SF-Bay Area is also the most expensive of the three regions ${ }^{(15)}$. Designed to understand regional differences in the determinants of food insufficiency, the current study will help inform the development of economic relief programmes during a crisis and guide the local delivery of services by federal food assistance programmes such as the Supplemental Nutrition Assistance Program (SNAP).

\section{Methods}

We used microdata from the CHHPS, a weekly national survey designed to track the effects of the coronavirus pandemic on people's lives and analysed data for California from phase 1 of data collection (12 weeks from 23 April 2020 to 21 July 2020$)^{(10)}$. Respondents across all geographic areas in our analysis were surveyed in the same time periods for each week of data collection. The survey used the Census Bureau's Master Address File to select a very large sample of housing units to allow for anticipated low response rates that could still yield estimates at the state and MSA levels. Sample sizes were determined to allow for a two-percentage point weekly change in key estimates to be detected at the national, state or MSA level with a $90 \%$ CI. Sampled households were contacted to participate in the CHHPS via email or text if an email address was not available. During phase 1 of CHHPS, survey participants could complete the survey for up to three consecutive weeks of data collection ${ }^{(16)}$. The survey was administered online and gathered demographic, social, economic and health information, including assessment of food insufficiency prior to initial efforts to lock down the economy (referred to as 'pre-pandemic' for ease of reading) and at the time of the survey. The following question was used to assess household food insufficiency: 
Getting enough food can also be a problem for some people. Which of these statements best describes the food eaten in your household before March 13, 2020 [repeated for the 'last 7 days']? Select only one answer.

- Enough of the kinds of food (I/we) wanted to eat

- Enough, but not always the kinds of food (I/we) wanted to eat

- Sometimes not enough to eat

- Often not enough to eat

Food insufficiency was operationally defined to include respondents who 'sometimes' or 'often did not have enough to eat'.

We used logistic regression to evaluate the likelihood that a respondent was food insufficient. The models include socio-economic and demographic factors associated with food insufficiency, specifically, respondent age, sex, race/ethnicity, education and employment status; household income, household size, number of children and recent loss of income; pre-pandemic food insufficiency (not enough to eat prior to 13 March 2020); and survey week (week 1 to week 12 , treated as an indicator variable). We built several models with the first for all California respondents testing MSA fixed effects to assess whether MSA differences remained after simultaneously controlling for confounding determinants of food insufficiency. We then stratified the data by MSA to examine metropolitan differences in the covariates. All analyses were weighted using weights provided by the Census Bureau to provide representative estimates at the state and MSA level for individuals aged 18 years and older.

\section{Results}

Table 1 presents summary characteristics of survey respondents. Differences in ethnicity, unemployment and household income between the two Southern California MSA (LA-Anaheim and Riverside-San Bernardino) and the Northern California MSA (SF-Bay Area) are notable. Forty-three percent and $47 \%$ of respondents in LAAnaheim and Riverside-San Bernardino, respectively, were Hispanic compared with only $20 \%$ in the SF-Bay Area which had higher percentages of Whites (43\%) and Asians (23\%). Compared with the SF-Bay Area, household income among respondents was lower in Riverside-San Bernardino and LA-Anaheim where $15 \%$ had annual incomes of $<\$ 25000$, and only 18 and $25 \%$, respectively, had incomes higher than $\$ 100$ 000. In comparison, only $9 \%$ of SF-Bay respondents had household incomes $<\$ 25000$ a year, while $44 \%$ had incomes of more than $\$ 100000$ a year.

Education levels were lowest among respondents in Riverside-San Bernardino where only $19 \%$ had a college degree compared with $32 \%$ in LA-Anaheim and $47 \%$ in
SF-Bay Area. Similar to the data reported above, during the 12 weeks of the survey, respondents in LA-Anaheim and Riverside-San Bernardino experienced higher unemployment rates than respondents in the SF-Bay Area ( $38 \%, 38 \% v .27 \%$, respectively). Pre-pandemic food insufficiency rates were highest among respondents in Riverside-San Bernardino (12\%) compared with $10 \%$ in LA-Anaheim and $8 \%$ in SF-Bay Area.

Over the initial months of the COVID-19 crisis from April to July 2020, more than three million California adults reported experiencing household food insufficiency, an increase of $22 \%$ from the pre-pandemic rate of $9 \%$ (Fig. 1). Consistent with the pattern observed prior to the COVID-19 crisis, food insufficiency rates were highest in Riverside-San Bernardino (13\%) closely followed by LAAnaheim (12\%), and lowest in the SF-Bay Area (9\%). Given that LA-Anaheim is the second most populous MSA in the nation, the actual number of adults experiencing household food insufficiency in LA-Anaheim was 4 times and 2.5 times that in SF-Bay Area and RiversideSan Bernardino, respectively. Table 2 presents food insufficiency rates by individual and household characteristics for California and each MSA. For California, rates of food insufficiency were highest among respondents who were Black, Hispanic, previously food insufficient, unemployed and lower income. When comparing across the three MSA, SF-Bay Area respondents generally reported lower or similar rates of food insufficiency compared with those in the other two MSA. There were two exceptions to this finding: lower income and Black respondents in the SF-Bay Area were much more likely to report household food insufficiency than those in LA-Anaheim and Riverside-San Bernardino.

\section{California}

Table 3 presents the results of the multivariate regression analysis for California and for each of the MSA. Among all California respondents, pre-pandemic food insufficiency was by far the strongest correlate of food insufficiency during the COVID-19 crisis. Adults experiencing household food insufficiency prior to COVID-19 were forty times more likely to be food insufficient during the 12 weeks of the survey. Among adults that experienced household food insufficiency during COVID-19, almost $80 \%$ were food insufficient prior to the pandemic.

Controlling for pre-pandemic food insufficiency, income remained a statistically significant predictor of food insufficiency during COVID-19 and showed a doseresponse relationship. The lowest income households $(<$ $\$ 25 \mathrm{k}$ ) were 2.5 times more likely to be food insufficient than households with incomes $>\$ 100 \mathrm{k}$. Food insufficiency also remained high among households in the next income group; households with incomes between $\$ 25000$ and $\$ 50000$ were 1.7 times more likely to be food insufficient compared to households with incomes $>\$ 100$ 000. These 
Table 1 Characteristics of study population by California geography; Census Household Pulse Survey, phase 1 (23 April-21 July 2020)*

\begin{tabular}{|c|c|c|c|c|}
\hline & California & $\begin{array}{l}\text { Los Angeles-Anaheim } \\
\text { MSA }\end{array}$ & $\begin{array}{l}\text { Riverside-San Bernardino } \\
\text { MSA }\end{array}$ & $\begin{array}{c}\text { San Francisco-Bay Area } \\
\text { MSA }\end{array}$ \\
\hline Unweighted $n$ & 76008 & 22240 & 15540 & 20095 \\
\hline $\begin{array}{l}\text { Weighted Sample† (percentage of California } \\
\text { sample) }\end{array}$ & 100 & 35 & 13 & 12 \\
\hline \multicolumn{5}{|l|}{ Individual characteristics } \\
\hline Female (\%) & 51 & 49 & 50 & 50 \\
\hline Median age (years) & 46 & 44 & 46 & 46 \\
\hline \multicolumn{5}{|l|}{ Race/ethnicity (\%) } \\
\hline White & 39 & 31 & 34 & 43 \\
\hline Black & 6 & 6 & 8 & 8 \\
\hline Hispanic & 36 & 43 & 47 & 20 \\
\hline Asian & 14 & 17 & 7 & 23 \\
\hline Bachelor's degree or higher (\%) & 32 & 32 & 19 & 47 \\
\hline Pre-pandemic food insufficient (\%) & 9 & 10 & 12 & 8 \\
\hline Recently lost employment income (\%) & 55 & 60 & 59 & 49 \\
\hline Unemployed (\%) & 34 & 38 & 38 & 27 \\
\hline \multicolumn{5}{|l|}{ Household characteristics } \\
\hline \multicolumn{5}{|l|}{ Household income (\%) } \\
\hline$<\$ 25 \mathrm{~K}$ & 15 & 17 & 16 & 8 \\
\hline$\$ 25 \mathrm{~K}-\$ 50 \mathrm{~K}$ & 26 & 28 & 31 & 16 \\
\hline$\$ 50 \mathrm{~K}-\$ 100 \mathrm{~K}$ & 27 & 26 & 31 & 22 \\
\hline$\$ 100 K+$ & 33 & 30 & 22 & 54 \\
\hline Median household size & 3 & 4 & 4 & 3 \\
\hline Median number of kids & 2 & 2 & 2 & 2 \\
\hline \multicolumn{5}{|l|}{ Survey week $(\%)$} \\
\hline Week 1 (23 April-5 May) & $8 \cdot 3$ & $8 \cdot 7$ & $9 \cdot 0$ & $7 \cdot 8$ \\
\hline Week 2 (7 May-12 May) & $8 \cdot 3$ & 8.7 & $8 \cdot 7$ & 9.5 \\
\hline Week 3 (14 May-19 May) & $8 \cdot 3$ & $8 \cdot 8$ & $8 \cdot 1$ & $9 \cdot 7$ \\
\hline Week 4 (21 May-26 May) & $8 \cdot 3$ & $8 \cdot 3$ & $8 \cdot 4$ & $8 \cdot 8$ \\
\hline Week 5 (28 May-2 June) & $8 \cdot 3$ & $8 \cdot 7$ & $8 \cdot 2$ & 8.4 \\
\hline Week 6 (4 June-9 June) & $8 \cdot 3$ & $8 \cdot 1$ & $8 \cdot 7$ & 7.4 \\
\hline Week 7 (11 June-16 June) & $8 \cdot 3$ & $8 \cdot 6$ & $7 \cdot 7$ & $8 \cdot 1$ \\
\hline Week 8 (18 June-23 June) & $8 \cdot 3$ & $8 \cdot 1$ & $8 \cdot 2$ & $8 \cdot 0$ \\
\hline Week 9 (25 June-30 June) & $8 \cdot 3$ & $8 \cdot 1$ & $7 \cdot 9$ & $8 \cdot 6$ \\
\hline Week 10 (2 July-7 July) & $8 \cdot 3$ & $8 \cdot 2$ & $8 \cdot 3$ & $7 \cdot 8$ \\
\hline Week 11 (9 July-14 July) & $8 \cdot 3$ & $7 \cdot 5$ & $8 \cdot 7$ & $8 \cdot 0$ \\
\hline Week 12 (16 July-21 July) & $8 \cdot 3$ & $8 \cdot 2$ & $8 \cdot 3$ & $8 \cdot 0$ \\
\hline
\end{tabular}

MSA, metropolitan statistical area.

*Weighted data provide representative estimates at the MSA and state levels.

†Proportions for MSA do not add to $100 \%$ because additional households were surveyed in the state of California outside of the three MSA highlighted in these analyses.

two income categories included households in the bottom two income quintiles in California ${ }^{(17)}$.

Respondents with a Bachelor's degree or higher were half as likely to experience household food insufficiency during the COVID-19 crisis as those with lesser education, an association independent of income and race/ethnicity. Employment status was also highly associated with food insufficiency. Adults who recently lost employment income were more than twice as likely to be living in food insufficient households as those who did not experience recent loss of income. Sixteen percent of adults in California who lost employment income, and $21 \%$ of unemployed adults in California reported being food insufficient. For the state of California, the odds of experiencing household food insufficiency among those who were unemployed were 1.9 times higher than those who were employed. Being Black or Hispanic was not associated with increased odds, while being Asian was associated with decreased odds (OR: 0.68) of household food insufficiency compared with Whites, controlling for other socio-demographic characteristics. Survey week was included as a covariate to assess whether food insufficiency increased over the 12 weeks relative to week 1 (23 April-5 May 2020). As shown in Table 3, the odds of household food insufficiency increased each week but did not reach statistical significance until week 12 (16-21 July) when it was 1.6 times that in week 1 . The MSA fixed effects were not statistically significant.

\section{Regional differences}

Controlling for other factors, regional differences in the predictors of food insufficiency remained. While food insufficiency rates were much lower in the SF-Bay Area than in LA-Anaheim and Riverside-San Bernardino, disadvantaged households in the SF-Bay Area were more likely to be food insufficient. For example, SF-Bay Area households that were food insufficient prior to the COVID-19 crisis were fifty-five times more likely to be food insufficient during the crisis than food sufficient households, compared with forty times more likely statewide. Similarly, SF-Bay Area households in the bottom two income categories were 


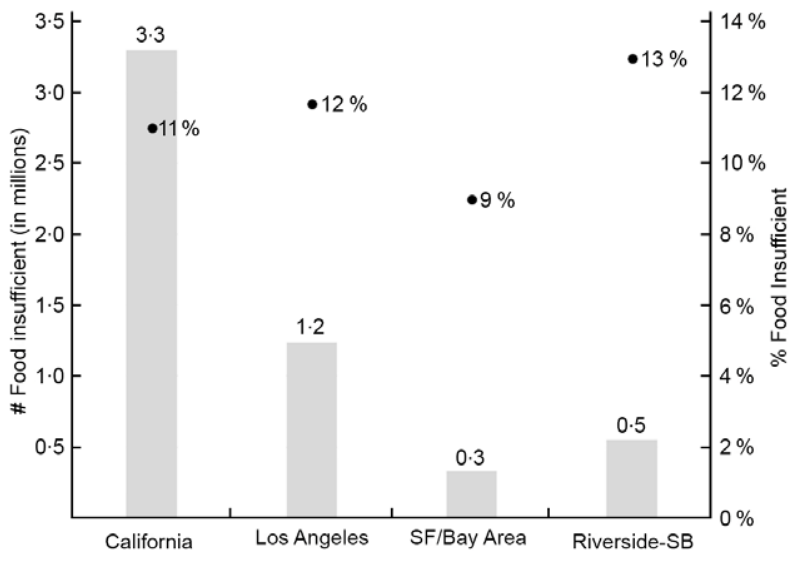

Fig. 1 Number and percentage of adults in food insufficient households in California metropolitan statistical areas (MSA), Census Household Pulse Survey, phase 1 (23 April-21 July 2020)*

*Data are weighted to provide representative estimates for adults aged 18 years and older living in households at the MSA and state level. MSA include San Francisco-Oakland-Berkeley, CA (SF/Bay Area), Los Angeles-Long Beach-Anaheim, CA (Los Angeles) and Riverside-San Bernardino-Ontario, CA (Riverside-SB). , \# food insufficient; $\%$, \% food insufficient.

about twice as likely to be food insufficient than their counterparts in LA-Anaheim and Riverside-San Bernardino. In fact, in the SF-Bay Area, adults in the second income category $(\$ 25-50 \mathrm{k})$ were only slightly less likely to be food insufficient than those in the lowest income category, likely reflecting the high cost of living in this metropolitan area. Finally, the SF-Bay Area was the only metropolitan area in which being Black - controlling for other characteristics - was associated with higher rates of food insufficiency. In particular, Black households living in the SF-Bay Area were $2 \cdot 8$ times more likely to be food insufficient than non-Hispanic White households. In comparison, Black households in Riverside-San Bernardino and LAAnaheim were not more likely to be food insufficient than non-Hispanic White households after controlling for other characteristics.

\section{Discussion}

Many of the findings are consistent with those of other studies of food insufficiency as well as food insufficiency in the context of the COVID-19 crisis $^{(7,8)}$. For California and all three metropolitan areas, adults with the greatest risk of household food insufficiency during the initial months of the COVID-19 crisis were those who were previously food insufficient. Respondent's employment status, low household income $(<\$ 25000$ and $\$ 25$ 000-\$50 000) and not having a Bachelor's degree were also risk factors for food insufficiency for the state and for each of the three MSA.

We noted that food insufficiency varied minimally from week to week except towards the end of phase 1 of the survey. In week 12 (16-21 July 2020), which coincided with the expiration of unemployment benefit enhancements as part of the federal CARES Act, the odds of experiencing household food insufficiency were 1.67 times higher than in week 1 of the survey for California. This difference was amplified for Riverside-San Bernardino. For the other two MSA, household food insufficiency rates changed minimally over the 12 weeks.

Table 2 Food insufficiency rates by California geography, Census Household Pulse Survey, phase 1 (23 April-21 July 2020*

\begin{tabular}{|c|c|c|c|c|}
\hline & California & $\begin{array}{l}\text { Los Angeles-Anaheim } \\
\text { MSA }\end{array}$ & $\begin{array}{c}\text { Riverside-San Bernardino } \\
\text { MSA }\end{array}$ & $\begin{array}{c}\text { San Francisco-Bay Area } \\
\text { MSA }\end{array}$ \\
\hline Unweighted $n$ & 76008 & 22240 & 15540 & 20095 \\
\hline Overall food insufficiency (\%) & 11 & 12 & 13 & 9 \\
\hline \multicolumn{5}{|l|}{ Individual characteristics (\%) } \\
\hline Female & 11 & 11 & 13 & 9 \\
\hline Age 65 or older & 5 & 5 & 7 & 4 \\
\hline \multicolumn{5}{|l|}{ Race/ethnicity } \\
\hline White & 7 & 6 & 10 & 3 \\
\hline Black & 22 & 20 & 22 & 32 \\
\hline Hispanic & 17 & 18 & 16 & 18 \\
\hline Asian & 6 & 6 & 8 & 5 \\
\hline Bachelor's degree or higher & 3 & 4 & 6 & 2 \\
\hline Pre-pandemic food insufficient & 77 & 74 & 77 & 78 \\
\hline $\begin{array}{l}\text { Recently lost employment } \\
\text { income }\end{array}$ & 16 & 17 & 19 & 14 \\
\hline Unemployed & 21 & 21 & 21 & 21 \\
\hline \multicolumn{5}{|l|}{ Household characteristics (\%) } \\
\hline \multicolumn{5}{|l|}{ Household income } \\
\hline$<\$ 25 \mathrm{~K}$ & 28 & 27 & 26 & 32 \\
\hline$\$ 25 \mathrm{~K}-\$ 50 \mathrm{~K}$ & 16 & 16 & 17 & 21 \\
\hline$\$ 50 \mathrm{~K}-\$ 100 \mathrm{~K}$ & 8 & 9 & 8 & 7 \\
\hline$\$ 100 \mathrm{~K}+$ & 1 & 2 & 2 & 1 \\
\hline School-age children at home & 14 & 15 & 14 & 16 \\
\hline
\end{tabular}

MSA, metropolitan statistical area.

*Weighted data provide representative estimates at the MSA and state levels. 
Table 3 Multivariate logistic regression models estimating food insufficiency by California geography, Census Household Pulse Survey, phase 1 (23 April-21 July 2020)†

\begin{tabular}{|c|c|c|c|c|c|c|c|c|}
\hline & \multicolumn{2}{|c|}{ California } & \multicolumn{2}{|c|}{$\begin{array}{c}\text { Los Angeles-Anaheim } \\
\text { MSA }\end{array}$} & \multicolumn{2}{|c|}{$\begin{array}{l}\text { Riverside-San } \\
\text { Bernardino MSA }\end{array}$} & \multicolumn{2}{|c|}{$\begin{array}{c}\text { San Francisco-Bay } \\
\text { Area MSA }\end{array}$} \\
\hline & OR & $95 \% \mathrm{Cl}$ & OR & $95 \% \mathrm{Cl}$ & OR & $95 \% \mathrm{Cl}$ & OR & $95 \% \mathrm{Cl}$ \\
\hline $\begin{array}{l}\text { Unweighted } n \\
\text { Individual characteristics }\end{array}$ & 76008 & \multicolumn{2}{|c|}{22240} & \multicolumn{2}{|c|}{15540} & \multicolumn{2}{|c|}{20095} & \\
\hline Female & 0.95 & $0.78,1.16$ & 0.95 & $0 \cdot 69,1 \cdot 30$ & 0.95 & $0.70,1.31$ & 1.03 & $0.68,1.55$ \\
\hline Age & 1.00 & $1.00,1.00$ & 1.00 & $1.00,1.00$ & 1.00 & $1.00,1.00$ & 1.00 & $1.00,1.00$ \\
\hline $\mathrm{Age}^{2}$ & 1.03 & $0.99,1.07$ & 1.04 & $0.98,1.11$ & 1.03 & $0.98,1.08$ & 0.98 & $0.91,1.05$ \\
\hline \multicolumn{9}{|l|}{ Race/ethnicity (Ref: White) } \\
\hline Black & 1.33 & $0.94,1.88$ & 1.65 & $0 \cdot 88,3 \cdot 12$ & 1.47 & $0.87,2.48$ & $2 \cdot 83$ & $1.51,5.33$ \\
\hline Hispanic & 0.94 & $0.73,1.21$ & 1.13 & $0.75,1.71$ & 0.78 & $0.55,1.12$ & 1.23 & $0.74,2.07$ \\
\hline Asian & 0.68 & $0.52,0.88$ & 0.67 & $0.42,1.08$ & 0.60 & $0.32,1 \cdot 15$ & $1 \cdot 17$ & $0.74,1.87$ \\
\hline Bachelor's degree or higher & $0.50^{*}$ & $0.42,0.60$ & $0.54^{*}$ & $0.40,0.74$ & $0.57^{*}$ & $0.37,0.89$ & $0.43^{\star}$ & $(0.29,0.65$ \\
\hline Pre-pandemic food insufficient & $40 \cdot 18^{\star}$ & $32 \cdot 19,50 \cdot 16$ & $33.75^{*}$ & $23 \cdot 40,48 \cdot 68$ & $46 \cdot 91^{*}$ & $33.58,65.52$ & $55 \cdot 33^{*}$ & $34 \cdot 30,89 \cdot 25$ \\
\hline Recently lost employment income & $2 \cdot 16^{*}$ & $1 \cdot 68,2 \cdot 77$ & $2 \cdot 40^{*}$ & $1.65,3.50$ & $2 \cdot 56^{\star}$ & $1 \cdot 73,3.80$ & $2 \cdot 36^{*}$ & $1.59,3.50$ \\
\hline Unemployed & $1 \cdot 87^{*}$ & $1.53,2.30$ & $2 \cdot 07^{*}$ & $1.51,2.85$ & $1.52^{*}$ & $1 \cdot 14,2 \cdot 04$ & $1 \cdot 30^{*}$ & $0.88,1.93$ \\
\hline \multicolumn{9}{|l|}{ Household characteristics } \\
\hline \multicolumn{9}{|l|}{ Household income (Ref: > \$100K) } \\
\hline$<\$ 25 \mathrm{~K}$ & $2 \cdot 52^{*}$ & $1.86,3.42$ & $2 \cdot 06^{*}$ & $1 \cdot 22,3.46$ & $2 \cdot 19^{\star}$ & $1.41,3.39$ & $3 \cdot 63^{*}$ & $1.96,6 \cdot 74$ \\
\hline$\$ 25 \mathrm{~K}-\$ 50 \mathrm{~K}$ & $1 \cdot 73^{*}$ & $1 \cdot 30,2 \cdot 29$ & $1 \cdot 72^{*}$ & $1.04,2.86$ & $1.52^{*}$ & $1 \cdot 01,2 \cdot 28$ & $3 \cdot 39^{\star}$ & $2 \cdot 07,5 \cdot 54$ \\
\hline$\$ 50 \mathrm{~K}-\$ 100 \mathrm{~K}$ & $1 \cdot 28$ & $0.98,1.67$ & 1.53 & $0.95,2.46$ & $1 \cdot 10$ & $0.71,1.71$ & 1.52 & $0.84,2.72$ \\
\hline Household size & $1 \cdot 11^{*}$ & $1.04,1 \cdot 18$ & 1.05 & $0.95,1.16$ & 1.14 & $1.00,1.29$ & 1.00 & $0.90,1.11$ \\
\hline Number of kids & 0.94 & $0.85,1.04$ & 1.05 & $0.90,1.22$ & 0.82 & $0.69,0.97$ & 1.05 & $0.87,1.26$ \\
\hline \multicolumn{9}{|c|}{ Metropolitan area (Ref: Rest of California) } \\
\hline Los Angeles-Anaheim MSA & 0.98 & $0.77,1.25$ & & & & & & \\
\hline Riverside-San Bernardino MSA & 1.02 & $0.80,1.29$ & & & & & & \\
\hline San Francisco-Bay Area MSA & 0.92 & $0 \cdot 71,1 \cdot 19$ & & & & & & \\
\hline \multicolumn{9}{|l|}{ Survey Week (Ref: week 1) } \\
\hline Week 2 (7 May-12 May) & $1 \cdot 21$ & $0 \cdot 68,2 \cdot 17$ & 1.32 & $0.45,3.88$ & 1.35 & $0 \cdot 64,2 \cdot 85$ & 0.98 & $0.35,2.74$ \\
\hline Week 3 (14 May-19 May) & $1 \cdot 15$ & $0.72,1.85$ & 1.49 & $0 \cdot 70,3 \cdot 17$ & 1.56 & $0.85,2 \cdot 83$ & 0.73 & $\cdot 28,1.92$ \\
\hline Week 4 (21 May-26 May) & $1 \cdot 12$ & $0.69,1.84$ & $1 \cdot 26$ & $0 \cdot 64,2.49$ & 0.82 & $0 \cdot 37,1 \cdot 79$ & 0.26 & $0.11,0.65$ \\
\hline Week 5 (28 May-2 June) & 1.24 & $0.78,1.97$ & 0.85 & $0.43,1.66$ & 1.37 & $0.78,2.40$ & 1.21 & $0.54,2 \cdot 70$ \\
\hline Week 6 (4 June-9 June) & $1 \cdot 11$ & $0.65,1.92$ & 1.18 & $0.53,2 \cdot 61$ & 1.08 & $0.60,1.97$ & 0.86 & $0.38,1.97$ \\
\hline Week 7 (11 June-16 June) & 1.29 & $0.80,2 \cdot 07$ & 1.11 & $0.55,2.22$ & 1.40 & $0.73,2.70$ & $1 \cdot 16$ & $0.50,2.67$ \\
\hline Week 8 (18 June-23 June) & $1 \cdot 23$ & $0 \cdot 75,2 \cdot 00$ & 0.90 & $0.46,1.79$ & $1 \cdot 16$ & $0.50,2.69$ & 0.72 & $0 \cdot 24,2 \cdot 15$ \\
\hline Week 9 (25 June-30 June) & $1 \cdot 33$ & $0.85,2.07$ & 1.40 & $0 \cdot 69,2 \cdot 82$ & 1.03 & $0 \cdot 60,1 \cdot 76$ & $1 \cdot 19$ & $0.56,2.49$ \\
\hline Week 10 (2 July-7 July) & $1 \cdot 16$ & $0.70,1.92$ & 1.18 & $0.55,2.52$ & 0.75 & $0.36,1.57$ & 0.86 & $0.40,1.84$ \\
\hline Week 11 (9 July-14 July) & 1.24 & $0.79,1.97$ & 1.35 & $0 \cdot 66,2 \cdot 76$ & 1.42 & $0 \cdot 76,2 \cdot 67$ & 0.58 & $0.25,1.36$ \\
\hline Week 12 (16 July-21 July) & $1.64^{*}$ & $1.04,2.59$ & 1.40 & $0.67,2.90$ & $2 \cdot 51^{*}$ & $1.38,4.56$ & 1.05 & $0.46,2.41$ \\
\hline
\end{tabular}

MSA, metropolitan statistical area; Ref, reference group.

${ }^{*} P<0.05$.

†Weighted analyses provide representative estimates at the MSA and state levels.

Our most notable finding was the regional differences in the effects of socio-demographic factors on household food insufficiency. In particular, the associations of sociodemographic factors with food insufficiency were magnified for SF-Bay Area households. For example, Black households residing in SF-Bay Area were more likely to suffer from food insufficiency during the COVID-19 crisis than Black households residing in the Southern California MSA, adjusting for income and education. Low-income households in the SF-Bay Area also had higher odds of food insufficiency (3.63) than low-income households in LAAnaheim and Riverside-San Bernardino (2.06 and 2.19, respectively). Geographic differences in food insufficiency experienced by Black and low-income households may be partially explained by differences in the benefits received from the CARES Act, and/or local responses to the pandemic. Rates of stimulus receipt from the CARES Act in our CHHPS study population differed by metropolitan area, with 83 and $87 \%$ of LA-Anaheim and Riverside-San
Bernardino residents receiving the stimulus, respectively, and just $72 \%$ of SF-Bay Area residents receiving the stimulus (data not shown).

As we noted previously, income inequality and the cost of living are high in the SF-Bay Area. Studies suggest an association between inequality and a host of negative effects, including adverse health outcomes. Income inequality has both direct and indirect effects ${ }^{(18,19)}$. It directly produces disparities in purchasing power for goods such as fresh produce, which are likely compounded in high-cost metropolitan areas with expensive housing ${ }^{(20,21)}$. Income inequality also may have indirect effects on food insufficiency through social factors that alter the relationship between individuals and the food environment. For example, it may influence social bonds among family members and neighbours, the distribution of political influence and the allocation of resources that affect the accessibility and reach of social service programmes including food assistance programmes ${ }^{(22)}$. 
Among households with children, geographic differences in participation in federal child nutrition programmes, such as the Special Supplemental Nutrition Program for Women, Infants and Children and the School Meals Program or in the implementation of these programmes during the COVID-19 crisis may partially explain metropolitan disparities in food insufficiency. Other scholars have observed that simultaneous participation in federal nutrition programmes, such as Women, Infants and Children and SNAP, is associated with lower risk of household food insecurity ${ }^{(23)}$. Differences in the implementation of these two programmes, for example, in outreach activities or in the application process, may explain varying coverage rates (defined as the percentage of those eligible who are enrolled in the programme).

Local responses to the waivers and flexibilities provided to school meals and child nutrition programmes under the Families First Coronavirus Response Act, passed in March 2020, varied considerably. These waivers and flexibilities allowed for the combination of food service operations from multiple entities to serve meals at a centralised location during school closures. Some local school districts provided free meals to all students while some others such as the San Francisco Unified School District provided free meals to students and their siblings ${ }^{(24)}$. Notably, the Los Angeles Unified School District, one of the largest in the nation, responded by providing free food at 'Grab and Go' food centres not only to students but to community members as well ${ }^{(25)}$. In addition, the presence of an active local food policy council may have supported efforts of the Los Angeles Regional Food Bank to widely distribute food through community-based organisations including faithbased entities ${ }^{(26,27)}$. It is likely that having an established infrastructure and network prior to the pandemic may have allowed some school districts to respond more effectively to the sudden increases in food insecurity brought about by the pandemic.

Interestingly, the number of children in the household was inversely associated with the odds of food insufficiency in Riverside-San Bernardino where the average household size is 3.3 compared with 3.0 in LA-Anaheim and 2.7 in SF-Bay Area. Because SNAP benefits increase with household size, it is possible that the lower odds of food insufficiency in Riverside-San Bernardino among low-income households may be partially due to receipt of higher SNAP benefits. Unfortunately, this phase of the CHHPS did not gather information on SNAP participation. The reach of SNAP, the largest federal food assistance programme which serves about 35.7 million Americans and costs about $\$ 60$ billion annually ${ }^{(28)}$, varies widely among states. SNAP in California (also known as 'CalFresh') has one of the lowest coverage rates (defined as the percentage of the population who is eligible to participate in the programme) in the nation averaging about $71 \%$ in 2017 compared with $84 \%$ for the USA. ${ }^{(29)}$ Further, coverage rates vary widely among the fifty-eight counties in California where, unlike most other states, counties are given considerable autonomy in administering the SNAP programme; this may account for differences in reach and application rates. In 2018, SNAP coverage rates for SF-Bay Area counties ranged from 36 to $71 \%$, which were considerably lower than those for the other two MSA ${ }^{(30)}$. Coverage rates for counties making up the LA-Anaheim and Riverside-San Bernardino MSA ranged from 59 to $74 \%$ and 68 to $92 \%$ respectively, with San Bernardino County recording one of the highest coverage rates in the state ${ }^{(30)}$.

Data from phase 2 of the CHHPS (19 August-26 October 2020) show similar regional differences in SNAP participation. Starting in this second phase of data collection, the Census Bureau asked respondents about SNAP participation. From mid-August through September 2020, 32 and $35 \%$ of respondents in households earning $<\$ 25000 \mathrm{a}$ year received SNAP in Riverside-San Bernardino and LAAnaheim MSA, respectively, compared with only $27 \%$ in the SF-Bay Area. This regional difference in coverage rates is even wider among households earning between $\$ 25 \mathrm{~K}$ and $\$ 50 \mathrm{~K}: 22 \%$ received SNAP in San BernardinoRiverside, $19 \%$ in LA-Anaheim and just $12 \%$ in the SFBay Area. Hence, higher food insufficiency in the SF-Bay Area among vulnerable population groups may partially reflect less effective SNAP administration and outreach in that region, factors that are likely to influence SNAP participation. Some of the lowest coverage rates for SNAP in the country are reported by counties in the SF-Bay Area. Understanding the reasons for these low coverage rates in this generally affluent region in the country may help address health disparities in regions where there are widening income disparities between the 'haves' and 'have-nots'.

While the CHHPS data and the current analysis were useful in tracking food insufficiency during the course of the pandemic, they do have limitations. First, the CHHPS was administered online, so populations without access to the internet may be under-represented in the study sample. Second, the few questions on food insufficiency do not fully align with the larger concept of 'food insecurity' used by the US Department of Agriculture, likely underreporting the percentage of households that have enough food to lead healthy and active lives. Third, the first phase of data collection did not include information on the receipt of food assistance programme benefits such as from SNAP. Finally, the sampling design did not allow for analyses by counties, which in the case of California would have allowed for more targeted monitoring of food insecurity and the impact of established food assistance programmes such as SNAP.

\section{Conclusions}

Our findings show regional differences in the association of various socio-demographic factors with food insufficiency 
risk. In particular, disadvantaged households in the SF-Bay Area - where income and educational levels are higher, but income inequality and cost of living are also higher - seem to be at higher risk for food insufficiency. Existing federal food assistance programmes can play an important role in addressing food insecurity in times of crisis, especially for low-income households. Having the administrative structure to effectively implement financial assistance programmes, SNAP and other food assistance programmes and quickly respond to changes in policy provisions is essential for mitigating both the immediate effects of a crisis such as the COVID-19 pandemic and the longer-term effects of structural inequities on food security. Food insecurity increases the risk of obesity and diet-related noncommunicable diseases over the life-course ${ }^{(31)}$, and finding ways to increase the reach of SNAP and other federal assistance programmes during this pandemic may help to decelerate widening disparities in health and perhaps even reverse its course.

\section{Acknowledgements}

Acknowledgements: The authors benefited from facilities and resources provided by the California Center for Population Research at UCLA (CCPR), which receives core support (P2C-HD041022) from the Eunice Kennedy Shriver National Institute of Child Health and Human Development (NICHD). Financial support: This research received no specific grant from any funding agency, commercial or not-for-profit sectors. Conflict of interest: There are no conflicts of interest. Authorship: E.B. and M.C.W. designed the study. M.P. analysed the data. E.B., M.C.W., L.A.N. and M.P. drafted the manuscript. All authors reviewed the results and approved the final version of the manuscript. Ethics of buman subject participation: The current study was determined to be exempt from IRB review by the UCLA Office of the Human Research Protection Program.

\section{Supplementary material}

For supplementary material accompanying this paper visit https://doi.org/10.1017/S1368980021001889

\section{References}

1. Dunn CG, Kenney E, Fleischhacker SE et al. (2020) Feeding low-income children during the COVID-19 pandemic. NEngl J Med 382, e40.

2. Mead D, Random K, Reed SB et al. (2020) The impact of the COVID-19 pandemic on food price indexes and data collection. Mon Labor Rev US Bur Labor Stat 143, 1.
3. National Research Council (2006) Food Insecurity and Hunger in the United States: An Assessment of the Measure. Washington, DC: The National Academies Press.

4. Gundersen C \& Ziliak JP (2015) Food insecurity and health outcomes. Health Aff 34, 1830-1839.

5. Fitzpatrick KM, Harris C \& Drawve G (2020) Assessing U.S. Food Insecurity in the United States during COVID-19 Pandemic. University of Arkansas. https://fulbright.uark. edu/departments/sociology/research-centers/communityfamily-institute/_resources/community-and-family-institute/ revised-assessing-food-insecurity-brief.pdf (accessed November 2020).

6. Schanzenbach D \& Tomeh N (2020) State Levels of Food Insecurity During the COVID-19 Crisis. Northwestern University. https://www.ipr.northwestern.edu/documents/ reports/ipr-rapid-research-reports-app-visualizes-foodinsecurity-14-july-2020.pdf (accessed July 2020).

7. Coleman-Jensen A, Rabbitt MP, Gregory CA et al. (2020) Household Food Security in the United States in 2019. U.S. Department of Agriculture, Economic Research Service. https://www.ers.usda.gov/webdocs/publications/99282/err275.pdf? $v=3122.6$ (accessed September 2020).

8. Schanzenbach D (2020) Not Enough to Eat: COVID-19 Deepens America's Hunger Crisis. Food Research \& Action Center. https://frac.org/wp-content/uploads/NotEnough-to-Eat_Hunger-and-COVID.pdf (accessed September 2020).

9. de la Haye K, Miller S, Livings M et al. (2020) The Impact of COVID-19 on Food Insecurity in Los Angeles County: April to July 2020. University of Southern California. https://publicexchange.usc.edu/food-insecurity-april-tojune/ (accessed September 2020).

10. US Census Bureau (2020) Household Pulse Survey Public Use File (PUF). https://www.census.gov/programssurveys/household-pulse-survey/datasets.html (accessed August 2020).

11. U.S. Department of Labor Unemployment Insurance Weekly Claims Data (2020). https://oui.doleta.gov/unemploy/claims. asp (accessed October 2020).

12. U.S. Bureau of Labor Statistics (2020) Metropolitan Area Employment and Unemployment - March 2020. https:// www.bls.gov/news.release/archives/metro_04292020.htm (accessed April 2020).

13. U.S. Bureau of Labor Statistics (2020) Metropolitan Area Employment and Unemployment - May 2020. https:// www.bls.gov/news.release/archives/metro_07012020.htm (accessed July 2020).

14. Berube A (2018) City and Metropolitan Income Inequality Data Reveal Ups and Downs through 2016. Washington, DC: Brookings Institution.

15. U.S. Bureau of Economic Analysis GDP \& Personal Income, Regional Price Parities by MSA, 2018. https://apps.bea.gov/ itable/iTable.cfm?ReqID $=70 \&$ step $=1$ (accessed November 2020).

16. U.S. Census Bureau Household Pulse Survey Technical Documentation. https:/www.census.gov/programs-surveys/ household-pulse-survey/technical-documentation.html (accessed November 2020).

17. U.S. Census Bureau American Community Survey, 2019 American Community Survey 1-Year Estimates, Table B19080. https://data.census.gov/cedsci/ (accessed October 2020).

18. Wilkinson RG \& Pickett KE (2006) Income inequality and population health: a review and explanation of the evidence. Soc Sci Med 62, 1768-1784.

19. Pickett KE \& Wilkinson RG (2015) Income inequality and health: a causal review. Soc Sci Med 128, 316-326.

20. Cohen N (2019) SNAP at the community scale: how neighborhood characteristics affect participation and food access. Am J Public Health 109, 1646-1651. 
21. Gascon C \& Spewak A (2018) Why does cost of living vary so much? Housing, housing, housing. FRED Blog. https:// fredblog.stlouisfed.org/2018/07/why-does-cost-of-livingvary-so-much/ (accessed December 2020).

22. Truesdale BC \& Jencks C (2016) The health effects of income inequality: averages and disparities. Annu Rev Public Health 37, 413-430.

23. Jensen HH, Kreider B \& Zhylyevskyy O (2019) Investigating treatment effects of participating jointly in SNAP and WIC when the treatment is validated only for SNAP. South Econ $J$ 86, 124-155.

24. Nutrition \& School Meals San Francisco Unified School District (2021). https://www.sfusd.edu/services/healthwellness/nutrition-school-meals (accessed April 2021).

25. Anthony A, Martichenko A \& Zheng P (2020) LAUSD meal plan supports Los Angeles community during COVID-19. USC Annenberg Media. http://www.uscannenbergmedia. com/2020/10/12/lausd-meal-plan-supports-los-angelescommunity-during-covid-19/ (accessed April 2021).

26. COVID-19 Resources for LA Los Angeles Food Policy Council (2021). https://www.goodfoodla.org/covid19 (accessed April 2021).
27. Los Angeles Regional Food Bank (2021) How the LA Food Bank Fought Hunger in 2020: A Year in Review. https:// www.lafoodbank.org/stories/2020-in-review/ (accessed April 2021).

28. Tiehen L (2020) The Food Assistance Landscape: Fiscal Year 2019 Annual Report. U.S. Department of Agriculture, Economic Research Service. https://www.ers.usda.gov/ webdocs/publications/99026/eib-218.pdf?v=6500 (accessed September 2020).

29. Cunnyngham K (2019) Reaching Those in Need: Estimates of State SNAP Participation Rates in FY 2016. U.S. Department of Agriculture, Food and Nutrition Service. https://www. fns.usda.gov/snap/reaching-those-need-estimates-statesupplemental-nutrition-assistance-program-participation-rates-fy (accessed August 2020).

30. California Department of Social Services CalFresh Data Dashboard (2021). https://www.cdss.ca.gov/inforesources/ data-portal/research-and-data/calfresh-data-dashboard (accessed November 2020).

31. Bukhman G (2015) Food Insecurity and Noncommunicable Disease among the Poorest. Food Insecurity Public Health. Boca Raton, FL: CRC Press, Taylor \& Francis Group. 